\title{
Ultrasonic Polymerization of Poly(vinylpyrrolidone)
}

\author{
Shinobu Koda, * Atsushi SuzuKi, and Hiroyasu Nomura \\ Department of Chemical Engineering, School of Engineering, \\ Nagoya University, 464-01, Japan
}

(Received April 13, 1995)

KEY WORDS Ultrasonic Polymerization / Poly(vinylpyrrolidone) /

\begin{abstract}
Recently, chemical reactions under ultrasonic irradiation have opened a new way to synthetic chemistry. ${ }^{1}$ Various chemical reactions $^{2,3}$ are accelerated by high power ultrasonic irradiation in the frequency range from $20 \mathrm{kHz}$ to $1 \mathrm{MHz}$ and in some cases, a new chemical reaction is initiated. In the field of polymer chemistry, many studies of ultrasonic irradiation effects on polymer solution have been carried out and much attention has been devoted to the ultrasonic degradation of polymer chains. ${ }^{4}$ Monomer and polymer radicals are produced when high power ultrasound is irradiated into monomer or polymer solutions. ${ }^{5}$ Therefore, polymerization and copolymerization are accelerated by ultrasonic irradiation and sometimes proceed without a catalyst.
\end{abstract}

Lorimer and Mason studied effects of ultrasound on polymerization of $N$-vinylpyrrolidone in aqueous solutions. ${ }^{6}$ They investigated the polymerization rate against composition of mixtures of water and pyrrolidone. However, detailed ultrasound effects on polymerization, such as the intensity, frequency, and irradiation time, have not been reported. In this work, the effects of the ultrasonic frequency, intensity and irradiation time on polymerization of $N$ vinylpyrrolidone in neat liquid without a catalyst were investigated quantitatively. To elucidate the ultrasonic effects on reactions, one must establish the proper experimental conditions, particularly effective ultrasonic intensity. As ultrasonic intensity depends on the shape of sample cells used and transducers, it is hard to specify the ultrasonic intensity by the output power of the ultrasonic generator. In this work, the amount of $\mathrm{NO}_{3}{ }^{-}$produced by ultrasonic irradiation in water was used as a measure of effective acoustic intensity in solutions.

The ultrasound of frequencies at 20 and 40 $\mathrm{kHz}$ was produced with an ultrasonic cleaning bath (Nippon Tokusyu Kogyou Co., Ltd., type UTK-600F). Maximum output power of the ultrasonic generator was $600 \mathrm{~W}$. The concave PZT transducer of the diameter $50 \mathrm{~mm}$ was used as an ultrasonic source at a frequency of $540 \mathrm{kHz}$. The output power of the ultrasonic generator was $80 \mathrm{~W}$. The concentration of $\mathrm{NO}_{3}{ }^{-}$produced by the ultrasonic irradiation in water was measured by the analytical method proposed by Wood et al. ${ }^{7)}$ The concentrations of $\mathrm{NO}_{3}{ }^{-}$produced ultrasonic irradiation for $1 \mathrm{~h}$ were $1.44 \times 10^{-6}, 0.85 \times$ $10^{-6}, 1.47 \times 10^{-6}$, and $4.36 \times 10^{-5} \mathrm{moll}^{-1}$ for output power of $300 \mathrm{~W}(20 \mathrm{kHz}), 300 \mathrm{~W}(40$ $\mathrm{kHz}), 600 \mathrm{~W}(40 \mathrm{kHz})$, and $80 \mathrm{~W}(540 \mathrm{kHz})$, respectively.

Vinylpyrrolidone ( hereafter abbreviated as VP) was purified by distillation under reduced pressure. Polymerization reaction was carried out at $50^{\circ} \mathrm{C}$. The sound wave was irradiated

* To whom correspondence should be addressed. 
into the cylindrical sample cell, made of Pyrex and the sample volume was $50 \mathrm{ml}$. The weightaverage molecular weight was obtained by gel permeation chromatography. A CCPD model (Tosoh Co., Ltd.) was used as the high pressure delivery pump. Pure water was used as the solvent and the flow rate was $1000 \mu \mathrm{min}^{-1}$. A differential refractometer was used as a detector, and TSK-GEL G3000PW and G5000PW as the columns (Tosoh Co., Ltd.) The details of the experimental procedure are given in our previous paper. ${ }^{8}$

No change in pure VP monomer was observed by irradiation of high power ultrasound at $540 \mathrm{kHz}$. Ultrasonic irradiation of the frequencies of 20 and $40 \mathrm{kHz}$ yields PVP polymer. At this stage, it is difficult to explain why polymerization under ultrasonic irradiation at $540 \mathrm{kHz}$ does not occur despite the very high ultrasound intensity. Polymerization without catalysts proceeds under ultrasonic irradiation at frequencies of 20 and $40 \mathrm{kHz}$. The reaction time dependence of the amount of polymer is shown in Figure 1. The amount of product increases linearly with reaction time. Polymerization stops immediately after cutting off the ultrasonic power and after that the amount of product remains unchanged. This means that the radicals are produced in pure VP monomer by ultrasonic irradiation. As shown in Figure 1, the polymerization rate depends on ultrasonic frequency and intensity. The ultrasonic irradiation effect on polymerization rate is pronounced at $40 \mathrm{kHz}$ in comparison with that at $20 \mathrm{kHz}$. The increase of ultrasonic intensity increases the reaction rate.

When the high power ultrasound is irradiated into liquids and solutions, cavitation bubbles are produced. The formation and collapse of the bubbles generate locally a reaction field at enormous temperature and pressure. The monomer radicals are formed in the reaction field and radical polymerization is initiated. According to this mechanism, Kruss et al. investigated the polymerization of methyl methacrylate under ultrasound irradiation. ${ }^{9}$
They derived the fractional conversion, $x(t)$ $(x(t)<0.04)$ as follows,

$$
x(t)=K_{1}(2[C])^{1 / 2}[M]_{0} t+K_{2}(2[C])[M]_{0} t^{2}
$$

where $[M]_{0}$ is the concentration of monomer, [C] concentration of cavitation bubbles, $K_{1}$ and $K_{2}$ constants as functions of reaction rate constants. Kruss et al. indicated that the fractional conversion is linearly proportional to the reaction time and the second term in eq 1 is negligible small. The fractional conversion is the ratio of the amount of polymer product to the initial monomer concentration. Thus, the amount of polymer product linearly changes with sonication time, as shown in Figure 1. This agrees with eq 1. Therefore, the polymerization of VP is initiated from monomer radicals formed under ultrasonic irradiation.

Figure 2 shows a plot of the average-weight molecular weight against sonication time for

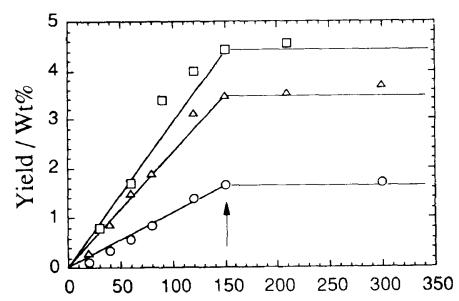

Figure 1.

Plot of the amount of product $v s$. reaction time for $100 \mathrm{wt} \%$ vinylpyrrolidone. Ultrasonic irradiation was terminated at $150 \mathrm{~min}$, as indicated by the arrow. $\bigcirc, 20 \mathrm{kHz}$ $\left(\mathrm{NO}_{3}{ }^{-}=1.44 \times 10^{-6} \mathrm{moll}^{-1}\right) ; \triangle, 40 \mathrm{kHz}\left(\mathrm{NO}_{3}{ }^{-}=0.85 \times\right.$ $\left.10^{-6} \mathrm{moll}^{-1}\right)$; $\square, 40 \mathrm{kHz}\left(\mathrm{NO}_{3}{ }^{-}=1.47 \times 10^{-6} \mathrm{moll}^{-1}\right)$.

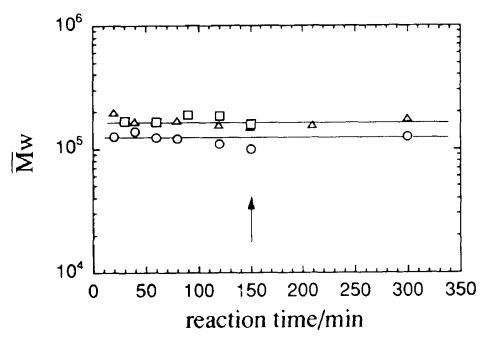

Figure 2. Average-weight molecular weight $v s$. reaction time for $100 \mathrm{wt} \%$ vinylpyrolidone. The symbols are the same as in Figure 1. 
polymerization of pure VP monomer. The value of polydispersity $\left(\bar{M}_{w} / \bar{M}_{n}\right)$ is around 2 within experimental errors and is almost independent of the reaction time. Thus, our attention was directed to the average-weight molecular weight. The molecular weights of PVP are almost independent of the reaction time and are around $10-20 \times 10^{4}$. These values are larger than those obtained from polymerization with catalysts of $\mathrm{H}_{2} \mathrm{O}_{2}$ and $\mathrm{NH}_{3}$ at $50^{\circ} \mathrm{C}$. The molecular weights of the latter case ranged from about $1 \times 10^{4}$ to $10 \times 10^{4} .{ }^{10}$ The thermal polymerization of pyrrolidone at $100^{\circ} \mathrm{C}$ gives a sample of average molecular weight of $16 \times 10^{410}$ which is comparable to those obtained from ultrasonic polymerization at $50^{\circ} \mathrm{C}$. Therefore, one advantage of ultrasonic polymerization is that polymerization at lower temperature is possible.

\section{REFERENCES}

1. S. V. Ley and C. M. R. Low, "Ultrasound in Synthesis," Springer-Verlag, Berlin-Hidelberg, 1989.

2. J. Lindley, in "Chemical with Ultrasound," T. J. Mason Ed., SCI, London, 1990, p 27.

3. R. S. Davidson, in "Chemical with Ultrasound," $T$. J. Mason Ed., SCI, London, 1990, p 65.

4. G. J. Price, in "Advances in Sonochemistry," Vol. 1, T. J. Mason Ed., JAI Press, London, 1990, p 231.

5. P. Kruss, in "Advances in Sonochemistry," Vol. 2, T. J. Mason Ed., JAI Press, London, 1991, p 1.

6. L. P. Lorimer and T. J. Mason, Proceedings, Ultrasonics International 87, Conference, Butterworths, Oxford, England, 1987, p 762.

7. E. D. Wood, F. A. J. Armstrong, and F. A. Richards, J. Mar. Biol. Ass. U.K., 47, 23 (1967).

8. S. Koda, H. Mori, K. Matsumoto, and H. Nomura, Polymer, 35, 30 (1994).

9. P. Kruss and T. J. Patraboy, J. Phys. Chem., 89, 3379 (1985).

10. T. Otsu, K. Matoba, S. Kikuchi, and I. Hirota, Yakugaku Zasshi, 75, 364 and 368 (1955). 